\title{
Acute relapsing pancreatitis (ARP) with pseudocyst formation due to sporadic hypertriglyceridemic pancreatitis in a 25 yrs old male: Case report
}

\author{
Hany Mohamed El-Barbary, MD FRCS \\ Department of General Surgery, Ain Shams University, Cairo, Egypt
}

\begin{abstract}
We wish to report a rare case of relapsing acute pancreatitis due to atypical sporadic hypertriglyceridemia (Frederickson's type IV) in a young male patient who presented first time to us with acute abdominal pain in the emergency department at Eldemerdash university hospital on January 2008.
\end{abstract}

\section{Introduction:}

Acute pancreatitis is defined as typical pancreatic abdominal pain (mid epigastric with radiation to the back) persisting for several hours, associated with elevation of serum amylase or lipase (to more than three times the normal levels). Acute Relapsing Pancreatitis is defined as two or more well-documented separate episodes of pancreatitis (pain and abnormal laboratory studies) that resolve between attacks. Evidence of pancreatitis should be documented by computed tomography (CT) or magnetic resonance imaging (MRI) during at least one episode. Acute relapsing pancreatitis (ARP) represents a challenging problem in the field of hepatobiliary and pancreatic disorders. It is associated with signify-cant morbidity, impairment in quality of life and a negative impact on medical costs. ${ }^{1}$

Acute relapsing pancreatitis may result from alcohol ingestion, cholelithiasis, autoimmune disease or congenital or acquired abnormalities of the ductal system. A minor fraction of patients may harbor a genetic defect predisposing them to acute relapsing pancreatitis. $^{2}$

Marked elevation of triglyceride levels appears to be causally linked to acute pancreatitis and hyperlipidemia is found in $12 \%$ to $38 \%$ of patients presenting with acute pancreatitis. Elevated cholesterol levels are not associated with pancreatitis. ${ }^{3}$

\section{Case report:}

A 25 yrs old average built male patient presented to the emergency room of Eldemerdash university hospital on January 2008, with severe abdominal pain, nausea and vomiting of two days duration. History revealed similar attack six years earlier for which he was admitted to ICU and explored elsewhere for the misdiagnosis of intestinal obstruction with resulting wound dehiscence and one month hospital stay for dressings. He gave history of binge alcohol drinking before that first attack only. He also gave history of elevated "pancreatic enzymes" which was discovered postoperatively. Following that, he was re-explored 4 months later due to recurrent abdominal pain and a segment of bowel was resected with a temporary stoma due to iatrogenic bowel injury. The patient had history of cigarette smoking of five cigarettes / day. His family history was insignificant. The patient remained well ever since.

On examination, the patient looked ill with agonizing abdominal pain. Patient's vitals were as follows: Pulse $110 \mathrm{bpm}$ regular, BP 130/85 $\mathrm{mmHg}$, Temp $37.5^{\circ} \mathrm{C}$, RR. 18/min. Clinically, there was no jaundice or cyanosis.

There was generalized abdominal tenderness, especially epigastric, with rebound tenderness and the abdomen showed several scars of previous laparotomies Figure(1). Bowel sounds were audible and there were stools on $\mathrm{P} / \mathrm{R}$.

Initial resussitative measures were undertaken and preliminary lab. and radiology ordered. The lab reported an unusual lactescent serum.

Laboratory results on admission were as 
follows: random blood sugar was $86 \mathrm{mg} / \mathrm{dl}$, white blood cells (WBCs) 10.2k/ml, Hb 12.4 $\mathrm{g} / \mathrm{dl}$, Plts $172 \mathrm{k} / \mathrm{ml}$, PT 11.6, INR 1.01, Amylase 2619 U/L, T.Bil 1.5 mg/dl, D.Bil 0.3 mg/dl, ALT $41 \mathrm{IU} / \mathrm{l}$, ALP $152 \mathrm{U} / \mathrm{L}$, S.Cr $1.5 \mathrm{mg} / \mathrm{dl}$, LDH $881 \mathrm{IU} / \mathrm{L}$, Total Calcium $8.8 \mathrm{mg} / \mathrm{dl}, \mathrm{Alb}$ $3.7 \mathrm{~g} / \mathrm{dl}$, Sodium $135 \mathrm{mmol} / \mathrm{L}$ and Potassium $5.3 \mathrm{mmol} / \mathrm{L}$.

Abdominal $X$ ray was insignificant Figure(2). Abdominal ultrasonography revealed mildly dilated bowel loops and $<20$ $\mathrm{ml}$ free fluid collection.

Management was conservative by NPO, NG tube, intravenous fluid and electrolyte management, antibiotics, pain relief, anti-ulcer measures and octeroid with a provisional diagnosis of pancreatitis for further evaluation.

After 14 hours fasting, due to the notion of the lactescent serum, a lipid profile was ordered as well as an abdominal CT with contrast to document the case of hyperlipidemic pancreatitis. Abdominal CT revealed bulky oedematous pancreas with blurred outline and fat striations as well as pseudocyst formation in the region of the body and uncinate process, denoting acute pancreatitis. There was reactionary pleuro pneumonic reaction Figure(3).

Serum triglycerides were markedly elevated $343 \mathrm{mg} / \mathrm{dl}$ (3.9 mmol/L), normal up to 150 $\mathrm{mg} / \mathrm{dl}$, with inversely low HDL but normal Total cholesterol, LDL and VLDL. The endocrinologists were consulted for the case and confirmed the diagnosis and advised strict lipaemic control for the patient as well as a diet regimen. Lab screening for his first degree relatives; parents and two male siblings were normal. Given the fact that a serum triglycerides of $>1000 \mathrm{mg} / \mathrm{dl}$ is usually needed to give rise to hypertriglyceridemic ARP, a diagnosis of sporadic- as opposed to familial- (atypical) hypertriglyceridemic (ICD-10: E 78-1) acute relapsing pancreatitis was concluded. This coincided with Frederickson's type IV classification of hyperlipidemia, a rare cause of metabolic pancreatitis.

The patient was symptom free after 3 days of admission and was discharged one week later under strict medical control to follow in OPD.

\section{Discussion:}

Acute pancreatitis secondary to hyperlipidemia is characterized by three presentations. All patients present with abdominal pain, nausea, and vomiting of hours to days duration. The most common presentation is a poorly controlled diabetic with a history of hypertriglyceridemia. The second presentation is the alcoholic found to have hypertriglyceridemia or lactescent serum on admission. The third, about $15-20 \%$ of patients, is the nondiabetic, nonalcoholic, nonobese patient with drug- or diet-induced hypertriglyceridemia. ${ }^{4}$ Hypertriglyceridemic acute pancreatitis is relapsing and its clinical course is more severe than lithiasic acute pancreatitis. The measurement of amylase and lipase levels is less useful in the diagnosis of hypertriglyceridemic than in lithiasic acute pancreatitis. ${ }^{5}$

A serum triglyceride (TG) level of more than 1,000 to $2,000 \mathrm{mg} / \mathrm{dL}$ in patients with type I, IV, or V hyperlipidemia (Fredrickson's classification), Table(1), is an identifiable risk factor. ${ }^{6}$ The typical clinical profile of hyperlipidemic pancreatitis (HLP) is a patient with a preexisting lipid abnormality along with the presence of a secondary factor (e.g., poorly controlled diabetes, alcohol use, or a medication) that can induce HTG. Less commonly, a patient with isolated hyperlipidemia (type V or I) without a precipitating factor presents with pancreatitis.

Interestingly, serum pancreatic enzymes may be normal or only minimally elevated, even in the presence of severe pancreatitis diagnosed by imaging studies. ${ }^{7}$

Current management of hyperlipidemic acute pancreatitis includes lipid lowering agents, diet control and plasmapheresis if diagnosed in the first 24-48 hrs. ${ }^{8}$

In our patient, clinical as well as laboratory data supported our initial working diagnosis of acute pancreatitis.

In the case of hypertriglyceridemic pancreatitis, elevated triglycerides (TG) hinders accurate calculation of the amylase and lipase levels. However, in this patient, this was not the case. Moreover, a lower serum level of TG was needed to trigger pancreatitis as in our 
patient this was elevated to only about 350 $\mathrm{mg} / \mathrm{dl}$, ie $1 / 3$ the reported value in the literature. This patient also did not show any other predisposing factors as DM or chronic alcoholism, etc. The lower TG level may be explained by two reasons; the first being the fasting course of the patient who presented 2 to 3 days from the onset of his symptoms where triglycerides level tend to fall, or it may signify the presence of a different phenotypic and genotypic variant involving the genetic expression of the pancreatic acinar cell membrane that renders it more vulnerable to lower levels of elevated triglycerides.

The genetic mechanism by which hypertriglyceridemia (HTG) leads to pancreatitis remains unclear. Several theories are postulated as mutational abnormalities in genes responsible for pancreatic ductal or acinar cell injury, including the cationic trypsinogen gene [protease, serine, 1 (trypsin 1) (PRSS1)], the pancreatic secretory trypsin inhibitor gene [serine peptidase inhibitor, Kazal type 1 (SPINK1)], the cystic fibrosis transmembrane conductance regulator gene [cystic fibrosis transmembrane conductance regulator (ATPbinding cassette subfamily $\mathrm{C}$, member 7 ) (CFTR)], and inflammation genes such as tumor necrosis factor [tumor necrosis factor, TNF superfamily, member 2 (TNF)], all are associated with hyperlipidemic pancreatitis (HLP) in patients with HTG. ${ }^{9}$

Pancreatic pseudocysts treatment is controversial since $25 \%$ to $50 \%$ of fluid collections after acute pancreatitis attack will be absorbed within 6 to 8 weeks spontaneously. Indications of non resolution of the cyst are the size of more than $6 \mathrm{~cm}$, multiple cysts, chronic pancreatitis and progressive cyst enlargement. ${ }^{10}$

Despite of the rarity of the condition, hypertriglyceridemic- acute relapsisng pancreatitis (HTG-ARP) is a recognized clinical condition that needs to be beard in mind and searched for. It should be differentiated from other causes of pancreatitis encountered by physicians. Most importantly this involves young practicing surgeons to prevent morbidity by unnecessary surgery and resulting mortality to this unfortunate group of patients.

Table (1): Frederickson classification of lipid disorders.

\begin{tabular}{|c|c|c|c|c|c|}
\hline Type & $\begin{array}{c}\text { Average of } \\
\text { overnight serum }\end{array}$ & $\begin{array}{l}\text { Elevated } \\
\text { particles }\end{array}$ & Associated clinical disorders & $\begin{array}{c}\text { Serum } \\
\text { TC }\end{array}$ & $\begin{array}{l}\text { Serum } \\
\text { TG }\end{array}$ \\
\hline I & $\begin{array}{l}\text { Creamy top } \\
\text { layer }\end{array}$ & Chylomicrons & $\begin{array}{l}\text { Lipoprotein lipase deficiency, } \\
\text { apolipoprotein C-II deficiency }\end{array}$ & & \\
\hline IIa & Clear & LDL & $\begin{array}{l}\text { Familial hypercholesterolemia, } \\
\text { polygenic hypercholesterolemia, } \\
\text { nephrosis, hypothyroidism, } \\
\text { familial combined } \\
\text { hyperlipidemia }\end{array}$ & & \\
\hline $\mathrm{IIb}$ & Clear & LDL, VLDL & $\begin{array}{l}\text { Familial combined } \\
\text { hyperlipidemia }\end{array}$ & & \\
\hline III & Turbid & IDL & Dysbetalipoproteinemia & & \\
\hline IV & Turbid & VLDL & $\begin{array}{l}\text { Familial hypertriglyceridemia, } \\
\text { familial combined } \\
\text { hyperlipidemia, sporadic } \\
\text { hypertriglyceridemia, diabetes }\end{array}$ & | & \\
\hline $\mathrm{V}$ & $\begin{array}{l}\text { Creamy top, } \\
\text { turbid bottom }\end{array}$ & $\begin{array}{l}\text { Chylomicrons, } \\
\text { VLDL }\end{array}$ & Diabetes & & \\
\hline \multicolumn{6}{|c|}{$\begin{array}{l}* I D L=\text { intermediate-density lipoproteins; } L D L=\text { low-density lipoproteins; } \\
T C=\text { total cholesterol } ; T G=\text { triglycerides } ; \operatorname{VDL}=\text { very low-density lipoproteins; } \\
\mathbf{I}=\text { increased } ; \mathbf{I} \mathbf{I}=\text { greatly increased } ;-=\text { normal } ;-\mathbf{I}=\text { normal or increased }\end{array}$} \\
\hline
\end{tabular}




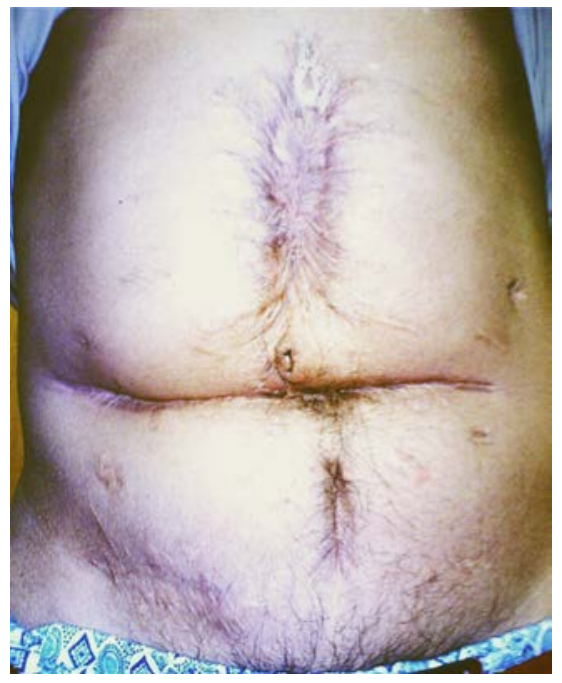

Figure (1): Appearance of the patient's abdomen on admission.

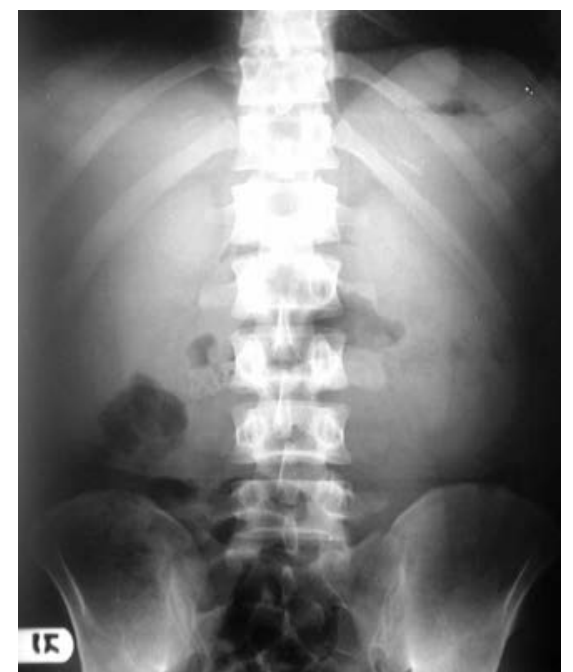

Figure (2): Erect abdominal X-Ray.

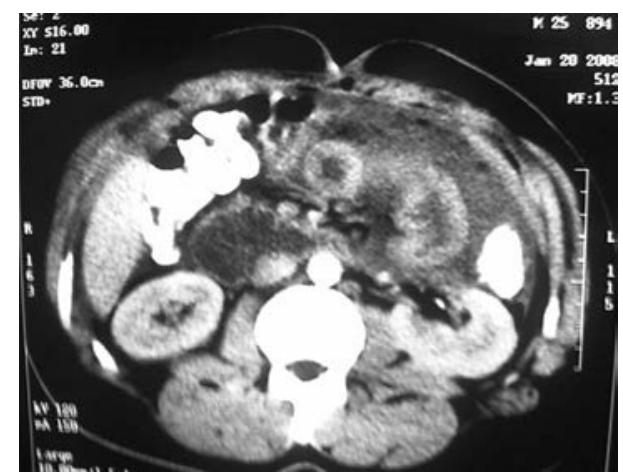

Figure (3): Abdominal CT showing pancreatic pseudocyst and fluid collection, denoting acute relapsing pancreatitis.

\section{References:}

1- Delhaye M: Acute Relapsing Pancreatitis. European Gastroenterology Review 2006; 51-53.

2- Georg L, Ulrike A, Christian K, Armin $\mathrm{R}$, Martin S, Olaf R et al.: Relapsing Pancreatitis due to a Novel Compound Heterozygosity in the CFTR Gene Involving the Second Most Common Mutation in Central and Eastern Europe [CFTRdele2,3(21 kb)]. Pancreatology. 2005; 5:92-96.

3- Toskes P: Hyperlipidemic pancreatitis. Gastroenterol Clin North Am 1990; 19:783791.

4- Fortson M, Freedman N and Webster D: Clinical assessment of hyperlipidemic pancreatitis. Am J Gastroenterol 1995; 90(12):2134-2139.

5- Navarro S, Cubiella J, Feu F, Zambón D, Fernández-Cruz L and Ros E: Hypertriglyceridemic acute pancreatitis. Is its clinical course different from lithiasic acute pancreatitis? Med Clin (Barc) 2004; 123(15):567-570.
6- Rade N and Daniel T: Hypertriglyceridemia. Jr Am B Fam Med 2006; 19:310-316.

7- Yadav D and Pitchumoni C: Issues in hyperlipidemic pancreatitis. J Clin Gastroenterol 2003; 36(1):54-62.

8- Iskandar S and Olive K: Plasmapheresis as an adjuvant therapy for hypertriglyceridemia-induced pancreatitis. Am J Med Sci 2004; 328(5):290-294.

9- Chang Y, Chang M, Su T, Liang P, Su Y, Kuo C et al: Association of cystic fibrosis transmembrane conductance regulator (CFTR) Mutation / Variant / Haplotype and Tumor Necrosis Factor (TNF) Promoter Polymorphism in: Hyperlipidemic Pancreatitis. 2008; 54(1):131-138.

10-A Michalopoulos, V Papadopoulos, S Apostolidis, D Paramythiotis, A Zatagias, N Harlaftis: Severe acute pancreatitis as a first symptom of primary hyperparathyroidism: A rare case report. The Internet Journal of Surgery 2007; Volume 9 Number 1. 